\title{
Styrene Polymerization by Nickel and Titanium Catalysts Based on Tris(pyrazolyl)borate Ligands
}

\author{
Maria C. A. Kuhn, Jaqueline L. da Silva, Adriana C. A. Casagrande and Osvaldo L. Casagrande Jr.* \\ Instituto de Química, Universidade Federal do Rio Grande do Sul, Av. Bento Gonçalves, 9500, \\ 91509-900 Porto Alegre-RS, Brazil
}

\begin{abstract}
A polimerização do estireno com uma série de complexos de níquel e titânio contendo ligantes tris(pirazolil)borato estericamente impedidos, $\mathrm{Tp}^{\mathrm{Ms}}=\mathrm{HB}\left(3\right.$-mesitila-pirazolil) ${ }_{3} \mathrm{e}$ $\mathrm{Tp}^{\mathrm{Ms}^{*}}=\mathrm{HB}\left(3\right.$-mesitila-pirazolil) ${ }_{2}$ (5-mesitila-pirazolil) foi estudada na presença do cocatalisador MAO sob várias condições de polimerização. Todos complexos mostraram-se ativos na polimerização do estireno produzindo quase exclusivamente poliestireno atático. As atividades catalíticas bem como as conversões com os complexos de níquel foram maiores em relação àquelas obtidas com os complexos de titânio. Maiores atividades foram encontradas a $80{ }^{\circ} \mathrm{C}$. As propriedades dos poliestirenos são substancialmente afetadas pelas condições de reação tais como temperatura de polimerização, tempo e razão molar [Al]/[M]. Os resultados de GPC mostram que o peso molecular $\left(\mathrm{M}_{\mathrm{w}}\right)$ dos poliestirenos é sensível à temperatura de polimerização variando de 16.300 a $138.300 \mathrm{~g} \mathrm{~mol}^{-1}$.
\end{abstract}

Styrene polymerization with a series of nickel and titanium complexes based on sterically hindered tris(pyrazolyl)borate ligands, $\mathrm{Tp}^{\mathrm{Ms}}=\mathrm{HB}\left(3-\right.$ mesityl-pyrazolyl) ${ }_{3}$ and $\mathrm{Tp}^{\mathrm{Ms}}=\mathrm{HB}(3-$ mesitylpyrazolyl $)_{2}(5$-mesityl-pyrazolyl) have been studied in the presence of MAO cocatalyst under various polymerization conditions. All complexes showed to be active for styrene polymerization producing almost exclusively atactic polystyrene. The catalytic activities as well as the styrene conversions with nickel complexes were higher than those with the titanium analogues. Higher activities were found at $80{ }^{\circ} \mathrm{C}$. Polystyrene properties are substantially affected by the reaction conditions such as temperature of polymerization, time, and $[\mathrm{Al}] /[\mathrm{M}]$ molar ratio. The GPC results showed that the molecular weight $\left(\mathrm{M}_{\mathrm{w}}\right)$ of the polystyrene is sensitive to the temperature of polymerization varying from 16,300 to $138,300 \mathrm{~g} \mathrm{~mol}^{-1}$.

Keywords: nickel, titanium, tris(pyrazolyl)borate ligand, polystyrene

\section{Introduction}

The chemistry of the non-metallocene catalysts has grown considerably over the past two decade, largely due to the remarkable variety of non-cyclopentadienyl ligands available and their high-performance in olefin polymerization. ${ }^{1}$ Many contributions have thus been made concerning this topic, especially using Group 4 and Group 10 metals for polymerization of ethylene, ${ }^{2}$ propylene, ${ }^{3}$ and in copolymerization reactions. ${ }^{4}$ Among linear $\alpha$-olefins, special attention has been devoted to the use of styrene as monomer for production of polystyrene considering their interesting chemical and physical properties for industrial applications. The polymerization process of styrene can

*e-mail: osvaldo.casagrande@ufrgs.br lead to three tactic structures which are depend on the nature of the catalyst precursor, including isotactic (iPS), syndiotactic (sPS) and atactic (aPS) polystyrenes. ${ }^{5}$ In contrast to the well-known isotactic polystyrene, which has a very low crystallization rate and is therefore useless for most industrial purposes, ${ }^{6}$ the syndiotactic polystyrene (sPS) shows a fast crystallization rate (more than an order of magnitude higher than that of iPS), a high crystallinity, a high melting point $\left(275^{\circ} \mathrm{C}\right)$ compared to $230^{\circ} \mathrm{C}$, superior heat and chemical resistance, high modulus of elasticity, and unique mechanical and/or electrical properties. These new properties, which are similar to those of some expensive engineering plastics, are the main reason for the interest in sPS as electronic and/or low-cost engineering plastics. ${ }^{7}$ The vast majority of single-site catalyst precursors reported for homogeneous polymerization of styrene have been mainly 
achieved with $\mathrm{Ti}^{8}$ and $\mathrm{Ni}^{9}$ transition metal complexes. Among them, the most active catalyst precursors for the synthesis of sPS, ${ }^{5,10}$ are based upon monocyclopentadienyl titanium complexes such as $\mathrm{Cp} * \mathrm{TiCl}_{3}$ activated with

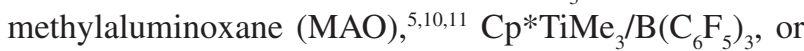
$\mathrm{Cp} * \mathrm{Ti}\left(\mathrm{CH}_{2} \mathrm{Ph}\right)_{3} /\left[\mathrm{C}_{6} \mathrm{H}_{5} \mathrm{NH}\left(\mathrm{CH}_{3}\right)_{2}\right]\left[\mathrm{B}\left(\mathrm{C}_{6} \mathrm{~F}_{5}\right)_{4}\right] .{ }^{12}$

In the recent years, we have been interested in exploring the chemistry of Group 4 and 10 complexes based on sterically hindered tris(pyrazolyl)borate ligands $(\mathrm{Tp}=$ generic substituted tris(pyrazolyl)borate) with the goal of developing novel olefin oligo- and polymerization catalysts. ${ }^{13}$ Tp' ligands are formally analogous to cyclopentadienyl (Cp) ligands in that both are six-electron-donor uninegative ligands. ${ }^{14}$ However, Tp' ligands are 3 -fold-symmetric $\sigma-\mathrm{N}$ donors and tend to form fac-octahedral complexes, while $\mathrm{Cp}$ ligands are typically 5 -fold-symmetric $\sigma$-C donors and tend to form tetrahedral complexes.

Our studies in this field have demonstrated that sterically hindered $\mathrm{Tp}{ }^{\prime} \mathrm{NiCl}(\mathbf{1 - 2})^{13}$ and $\mathrm{Tp}^{\prime} \mathrm{TiCl}_{3}(\mathbf{3 - 4})^{13}$ pre-catalysts $\left[\mathrm{Tp}=\mathrm{HB}(3 \text {-mesityl-pyrazolyl })_{3}\left(\mathrm{Tp}^{\mathrm{Ms}}\right)^{-}\right.$; HB(3-mesitylpyrazolyl $)_{2}\left(5\right.$-mesityl-pyrazolyl) $\left.\left(\mathrm{Tp}^{\mathrm{Ms} *}\right)^{-}\right]$show high catalytic activity for oligo- and polymerization of ethylene in the presence of methylaluminoxane (Figure 1).

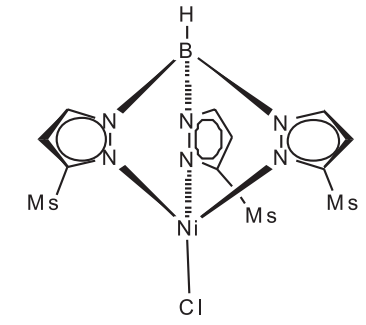

1

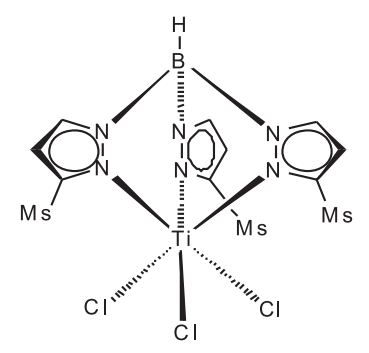

3

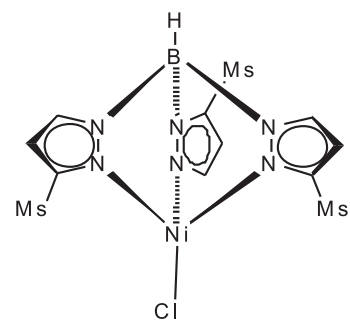

2

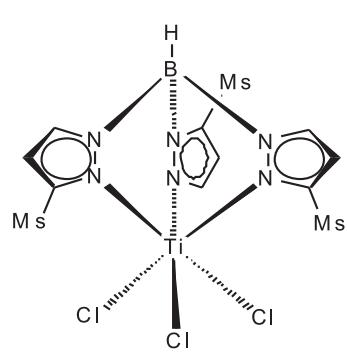

4
Ms $=2,4,6$-trimethylphenyl

Figure 1. Nickel and titanium catalysts based on tris(pyrazolyl) ligand.

Taking into account these aspects, we concentrate on exploring the possibility to expand the utility of our original catalysts to polymerization of aromatic alkenes. In this paper, we report the studies related to the use of 1-4 pre-catalysts in styrene polymerization. Studies related to the effect of some polymerization parameter (solvent, polymerization temperature, styrene concentration, time of polymerization, and aluminum concentration) on the activity and polystyrene properties will be presented.

\section{Experimental}

\section{Materials}

All manipulations were performed using standard vacuum line and Schlenk techniques under a purified argon atmosphere. Toluene and hexane were distilled from sodium-benzophenone ketyl under argon and degassed by freeze-thaw-vacuum cycles prior to use. $\mathrm{Tp}^{\mathrm{Ms}} \mathrm{NiCl}$ (1), $\mathrm{Tp}^{\mathrm{Ms}} \mathrm{NiCl}(\mathbf{2}), \mathrm{Tp}^{\mathrm{Ms}} \mathrm{TiCl}_{3}(\mathbf{3})$, and $\mathrm{Tp}^{\mathrm{Ms}} \mathrm{TiCl}_{3}$ (4) $\left(\mathrm{Tp}^{\mathrm{Ms}}=\mathrm{HB}\left(3\right.\right.$-mesityl-pyrazolyl ${ }_{3}^{-}$; $\mathrm{Tp}^{\mathrm{Ms}}=\mathrm{HB}$ (3-mesitylpyrazolyl $)_{2}(5 \text {-mesityl-pirazolyl) })^{-}$) were prepared according to procedures published in the literature. ${ }^{13}$ Styrene (Acros, $99.0 \%)$ as dried over $\mathrm{CaH}_{2}$, and freshly distilled. PMAO-IP (Akzo, 12.9 wt.\% Al solution in toluene) was used as received.

\section{General procedure for styrene polymerization}

To a $100 \mathrm{~mL}$ Schlenk flask the correct amounts of styrene, toluene and $\mathrm{MAO}$ were introduced sequentially and stirred for $10 \mathrm{~min}$. After complete thermal equilibration, the polymerization was initiated by adding a proper amount of pre-catalyst (1-4) as a toluene solution $(2 \mathrm{~mL})$. The mixture was stirred for a desired time, after which time $1 \mathrm{~mL}$ of methanol was added and the mixture stirred for $10 \mathrm{~min}$. The contents were then poured into acidified ethanol $(150 \mathrm{~mL})$. The obtained polymer was filtered and washed three times with acidified ethanol, then ethanol and water. The resulting polymers were dried overnight at $60^{\circ} \mathrm{C}$ in a vacuum to constant weight.

\section{Polymer characterization}

Polymer melting points $\left(\mathrm{T}_{\mathrm{m}}\right)$ were determined on a Thermal Analysis Instruments DSC-2010 calibrated with Indium, using a heating rate of $10{ }^{\circ} \mathrm{C} \mathrm{min}-1$ in the temperature range $40-280{ }^{\circ} \mathrm{C}$. The heating cycle was performed twice, but only the results of the second cycle are reported, since the former is influenced by the mechanical and thermal history of the samples. The molecular weight $\left(\mathrm{M}_{\mathrm{w}}\right)$ was evaluated by gel permeation chromatography (GPC) with the Waters $150 \mathrm{CV}$ system equipped with three columns Styragel HT3, HT4 and HT6 $\left(10^{3}, 10^{4}\right.$ and $10^{6} \AA$, respectively) and a refractive index detector. Analyses were undertaken using 1,2,4-trichlorobenzene as solvent 
(with $0.5 \mathrm{~g} \mathrm{~L}^{-1}$ of Irganox 10/10 as antioxidant) at $140^{\circ} \mathrm{C}$ and the molecular weights $\left(\mathrm{M}_{\mathrm{ws}}\right)$ were calculated using a universal calibration curve built with polystyrene standards (American Polymer Standard Corporation) and checked with polyethylene and polypropylene known samples.

\section{Results and Discussion}

Styrene polymerization studies involving tris(pyrazolyl) borate nickel catalysts

Styrene polymerization studies involving Tp' $\mathrm{NiCl}$ (1, $\left.\mathrm{Tp}=\mathrm{Tp}^{\mathrm{Ms}} ; \mathbf{2}, \mathrm{Tp}^{\prime}=\mathrm{Tp}^{\mathrm{Ms}}\right)$ were carried out in toluene at $30^{\circ} \mathrm{C}$ using methylaluminoxane (MAO) as cocatalyst. The polymerization results are summarized in Table 1. Initial studies carried out at $30{ }^{\circ} \mathrm{C}$ with MAO-to-Ni ratios of 500 showed that these catalyst systems are quite active.

The less sterically crowed pre-catalyst $\mathbf{2}$ is $c a$. 1.6 times more active than $\mathbf{1}$ under identical styrene polymerization conditions (Table 1, entry 6 vs 3). For both cases high styrene conversions have been found varying between $62.8 \%$ and $98.6 \%$. Quite different results have been found for 1-2 in ethylene dimerization reactions where the precatalyst $\mathbf{1}$, under MAO activation at $30^{\circ} \mathrm{C}$, is much more active $\left(\mathrm{TOF}=29.2 \times 10^{3} \mathrm{~h}^{-1}\right)$ than $\mathbf{2}\left(\mathrm{TOF}=1.8 \times 10^{3} \mathrm{~h}^{-1}\right) .^{13}$ These results suggest that the nature of the monomer play an influence on the activity. In this case, the lower activity of $\mathbf{1}$ in styrene polymerization can be associated to the presence of $\mathrm{Tp}^{\mathrm{Ms}}$ unit leaving the nickel metal center less
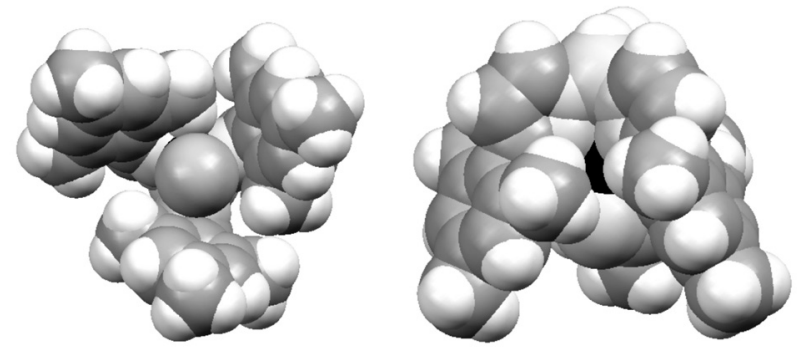

Figure 2. Space-filling model of $\mathrm{Tp}^{\mathrm{Ms}} \mathrm{NiCl}$ (1).

accessible to the coordination of styrene as can be seen in Figure $2 .{ }^{15}$

The properties of the resulting polystyrenes are shown in Table 1. DSC measurements of the polymers produced by 1-2/MAO show just a small endothermic peak centered at $103{ }^{\circ} \mathrm{C}$ corresponding to the glass transition temperature $\left(\mathrm{T}_{\mathrm{g}}\right)$. Moreover, the absence of peaks related to the melting temperature $\left(\mathrm{T}_{\mathrm{m}}\right)$ above $240{ }^{\circ} \mathrm{C}^{5}$ reveals the formation of atactic polystyrenes. It indicates that the activation of $\mathbf{1}$ and 2 with MAO does not lead to the formation of stereospecific active species.

GPC analyses of the atactic polymers show molecular weight distributions $\left(\mathrm{M}_{\mathrm{w}} / \mathrm{M}_{\mathrm{n}}\right)$ around 2, as predicted for single-site catalysts. The sterically crowded pre-catalyst 2 affords polystyrene with molecular weight $\left(\mathrm{M}_{\mathrm{w}}\right)$ of 52,600 that is slightly higher compare to that one obtained using $1\left(M_{w}=44,200\right)$. We believe at this stage that this increase of molecular weight is attributable to the steric bulkiness

Table 1. Styrene polymerization with 1-2/MAO systems ${ }^{\mathrm{a}}$

\begin{tabular}{|c|c|c|c|c|c|c|c|c|c|}
\hline Entry & Cat. & $\mathrm{t} / \mathrm{min}$ & $\mathrm{T} /{ }^{\circ} \mathrm{C}$ & {$[\mathrm{Al}] /[\mathrm{Ni}]$} & $\mathrm{PS} / \mathrm{g}$ & $\mathrm{A}^{\mathrm{b}}$ & Conv. $.^{\mathrm{c}} /(\%)$ & $\mathrm{M}_{\mathrm{w}}^{\mathrm{e}}\left(\times 10^{3}\right)$ & $\mathrm{M}_{\mathrm{w}} / \mathrm{M}_{\mathrm{n}}$ \\
\hline 1 & 1 & 15 & 30 & 500 & 0.13 & 520 & 11.3 & 56.2 & 2.3 \\
\hline 2 & 1 & 30 & 30 & 500 & 0.43 & 860 & 37.5 & 52.5 & 1.5 \\
\hline 3 & 1 & 60 & 30 & 500 & 0.72 & 720 & 62.8 & 44.2 & 2.1 \\
\hline 4 & 1 & 120 & 30 & 500 & 1.09 & 545 & 95.1 & 44.1 & 2.1 \\
\hline 5 & 1 & 240 & 30 & 500 & 1.12 & 280 & 97.8 & 45.2 & 2.3 \\
\hline 6 & 2 & 60 & 30 & 500 & 1.13 & 1130 & 98.6 & 52.6 & 2.0 \\
\hline $7^{\mathrm{d}}$ & 1 & 60 & 30 & 500 & 0.15 & 150 & 13.1 & 48.4 & 2.2 \\
\hline 8 & 1 & 60 & 0 & 500 & 0.18 & 180 & 15.7 & 88.1 & 1.6 \\
\hline 9 & 1 & 60 & 60 & 500 & 1.10 & 1100 & 96.0 & 33.2 & 1.6 \\
\hline 10 & 1 & 60 & 80 & 500 & 1.11 & 1110 & 96.8 & 16.3 & 1.9 \\
\hline 11 & 1 & 60 & 30 & 100 & - & - & - & - & - \\
\hline 12 & 1 & 60 & 30 & 200 & 0.31 & 310 & 27.0 & 56.6 & 1.7 \\
\hline 13 & 1 & 60 & 30 & 1000 & 0.95 & 950 & 82.9 & 53.4 & 2.0 \\
\hline 14 & 1 & 60 & 30 & 2000 & 0.77 & 770 & 67.2 & 53.1 & 2.1 \\
\hline
\end{tabular}

aReaction conditions: toluene $=2 \mathrm{~mL} ;[\mathrm{Ni}]=1 \mu \mathrm{mol} ;[\mathrm{Styr}] /[\mathrm{Ni}]=11000$. The results shown are representative of at least duplicated experiments. ${ }^{\mathrm{b}} \mathrm{kg}$ of PS mol $\left[\mathrm{Ni}^{-1} \mathrm{~h}^{-1}\right.$; ${ }^{\mathrm{c}}$ mass of polystyrene obtained/mass of styrene $\times 100 \%$; ${ }^{\mathrm{d}}$ addition of $8 \mathrm{~mL}$ of toluene; ${ }^{\mathrm{e}} \mathrm{g} \mathrm{mol}{ }^{-1}$. 
and electronic effect of mesityl substituents, which make the termination process such as $\beta$-hydride elimination or chain transfer reaction by $\mathrm{AlMe}_{3}$ less affordable.

Based on these encouraging preliminary results, complex 1 was selected for further optimization, investigating the influence of the styrene concentration, polymerization time, temperature, and $[\mathrm{Al}] /[\mathrm{Ni}]$ molar ratio. Interestingly, the activity of $\mathbf{1}$ decreases by a factor of nearly 5 when the polymerization is performed in the presence of higher amount of toluene (entry 7, $150 \mathrm{~kg}$ of PS mol $\left[\mathrm{Ni}^{-1} \mathrm{~h}^{-1}\right.$ ). This effect can be associated to a possible competition between the coordinating styrene and the solvent itself; however, a decrease of the styrene concentration from $5.5 \mathrm{~mol} \mathrm{~L}^{-1}$ to $1.1 \mathrm{~mol} \mathrm{~L}^{-1}$ (entry $3 v$ s. 7), which would induce catalyst decay, cannot be ruled out.

Evaluation of the polymerization time effect revealed that within $120 \mathrm{~min}$, the polymer yield reaches a maximum value. Then, over next $4.0 \mathrm{~h}$, the polymer yield remains at this upper limit $(95 \%)$ as showed in Figure 3. The time dependence of the $M_{w}$ and $M_{w} / M_{n}$ of polymers produced is also shown in Table 1. The molecular weight remained almost constant during the course of the polymerization indicating that chain-transfer reactions exist in the present polymerization system.

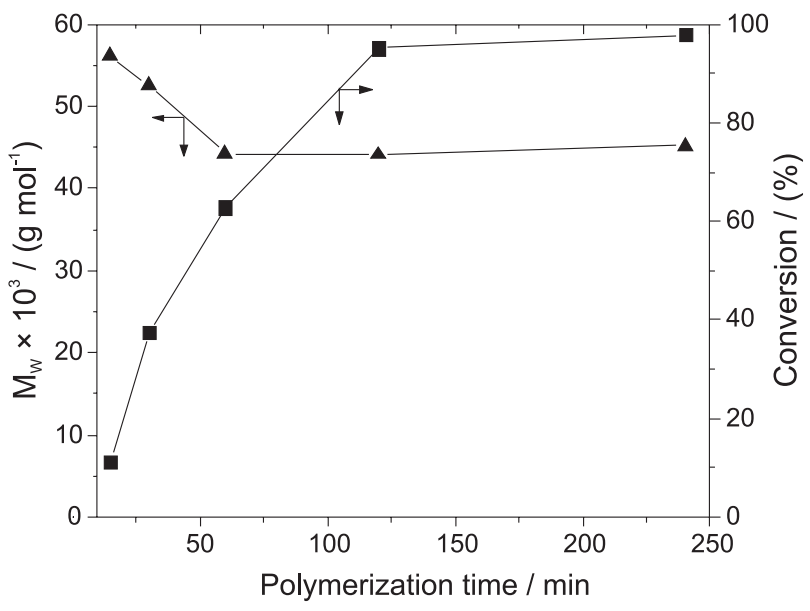

Figure 3. Dependence of polymerization activity and molecular weight on polymerization time with $\mathbf{1} / \mathrm{MAO}$ system at $30^{\circ} \mathrm{C}$ and using $[\mathrm{Al}] /[\mathrm{Ni}]$ molar ratio of 500 .

The polymerization activities of $\mathbf{1} / \mathrm{MAO}$ and polymer properties thus obtained are also dependent upon the polymerization temperature. As revealed by Figure 4, the catalytic activities increase as the polymerization temperature $\mathrm{T}_{\mathrm{p}}$ increases up to $80^{\circ} \mathrm{C}$. On the other hand, one can also notice that the molecular weight decreases with increasing polymerization temperature. This can be explained by the fact that the average molecular weights

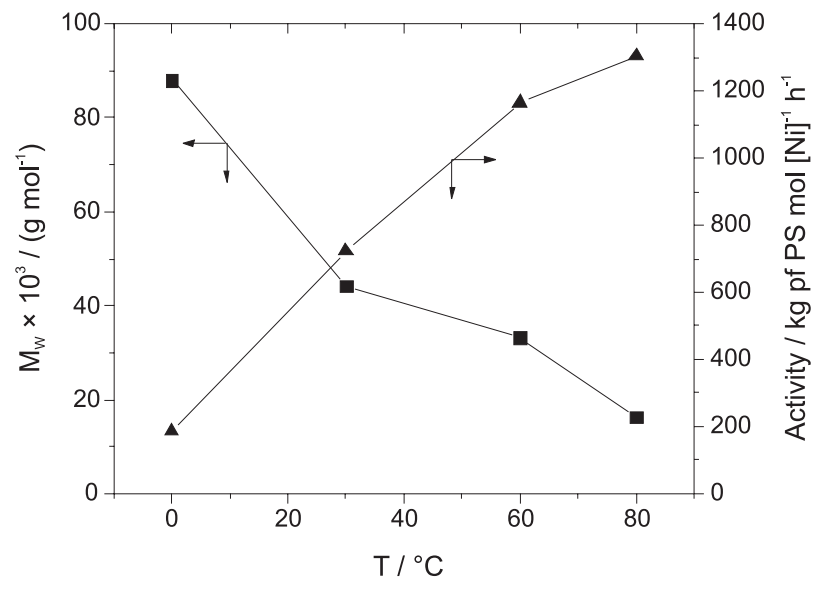

Figure 4. Dependence of polymerization activity and molecular weight on polymerization temperature with $1 / \mathrm{MAO}$ system at $30^{\circ} \mathrm{C}$ and using $[\mathrm{Al}] /[\mathrm{Ni}]$ molar ratio of 500 .

are mainly determined by the $\mathrm{k}_{\mathrm{p}} / \mathrm{k}_{\mathrm{tr}}$ ratio, where $\mathrm{k}_{\mathrm{tr}}$ increases with temperature faster than $\mathrm{k}_{\mathrm{p}}$ with the following decrease of $\mathrm{M}_{\mathrm{w}}$ with increasing temperature.

Entries 3 and 11-14 summarize styrene polymerizations by $\mathbf{1} / \mathrm{MAO}$ catalyst systems at various $[\mathrm{Al}] /[\mathrm{Ni}]$ molar ratios. When activated with 100 equivalents of MAO, complex 1 was not active. Increasing the aluminum concentration to 200 it was observed a moderate activity (310 kg of PS mol [Ni] $]^{-1} \mathrm{~h}^{-1}$, entry 12 ), which was increased upon using 500 (720 kg of PS mol $\left[\mathrm{Ni}^{-1} \mathrm{~h}^{-1}\right.$, entry 3$)$ and 1000 equivalents of MAO (950 kg of PS mol $\left[\mathrm{Ni}^{-1} \mathrm{~h}^{-1}\right.$, entry 13). A greater loading of MAO (2000 equivalents) led to lower activity (770 kg of PS mol $\left[\mathrm{Ni}^{-1} \mathrm{~h}^{-1}\right.$, entry 13). This effect is most likely due to the coordination of $\mathrm{AlMe}_{3}$, present in the MAO, to the active species disfavoring monomer coordination. ${ }^{16}$

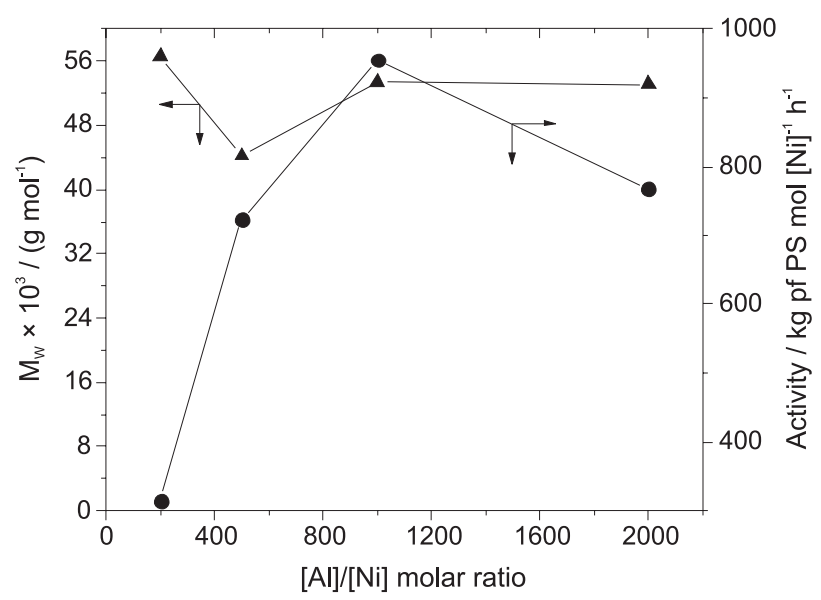

Figure 5. Dependence of polymerization activity and molecular weight on $[\mathrm{Al}] /[\mathrm{Ni}]$ molar ratio with $\mathbf{1} / \mathrm{MAO}$ system at $30^{\circ} \mathrm{C}$. 
Table 2. Styrene polymerization with 3-4/MAO systems ${ }^{\mathrm{a}}$

\begin{tabular}{lcccccccccc}
\hline Entry & Cat. & time $/ \mathrm{min}$ & $\mathrm{T} /{ }^{\circ} \mathrm{C}$ & {$[\mathrm{Al}] /[\mathrm{Ti}]$} & $\mathrm{PS} / \mathrm{g}$ & $\mathrm{A}^{\mathrm{b}}$ & Conv. $^{\mathrm{c}} /(\%)$ & $\mathrm{T}_{\mathrm{m}} /{ }^{\circ} \mathrm{C}$ & $\mathrm{M}_{\mathrm{w}}^{\mathrm{e}}\left(\times 10^{3}\right)$ & $\mathrm{M}_{\mathrm{w}} / \mathrm{M}_{\mathrm{n}}$ \\
\hline 15 & $\mathbf{3}$ & 60 & 60 & 500 & 0.11 & 22.4 & 1.9 & 268 & 97.3 \\
16 & $\mathbf{4}$ & 60 & 30 & 500 & - & - & - & - & - \\
17 & $\mathbf{4}$ & 60 & 60 & 500 & 0.13 & 26.0 & 2.3 & 267 & 92.5 \\
18 & 4 & 60 & 80 & 500 & 0.19 & 38.0 & 3.3 & 264 & 56.2 & 8.8 \\
19 & 4 & 60 & 60 & 1000 & 0.14 & 28.0 & 2.4 & 264 & 49.8 & 3.3 \\
20 & 4 & 15 & 60 & 500 & 0.07 & 13.0 & 1.2 & 265 & 38.8 & 6.2 \\
21 & 4 & 30 & 60 & 500 & 0.10 & 20.0 & 1.7 & 265 & 32.8 \\
22 & 4 & 240 & 60 & 500 & 0.21 & 11.0 & 3.6 & 268 & 138.3 & 3.2 \\
23 & 4 & 60 & 60 & 500 & 0.06 & 11.0 & 1.1 & 265 & 51.7 & 3.8 \\
\hline
\end{tabular}

aReaction conditions: toluene $=2 \mathrm{~mL} ;[\mathrm{Ti}]=5 \mu \mathrm{mol} ;[\mathrm{Styr}] /[\mathrm{Ti}]=11000$. The results shown are representative of at least duplicated experiments. ${ }^{\mathrm{b}} \mathrm{kg}$ of PS mol[Ti $]^{-1} \mathrm{~h}^{-1}$. ${ }^{\mathrm{c}}$ mass of polystyrene obtained/mass of styrene $\times 100 \%$. ${ }^{\mathrm{d}}[\mathrm{Sty}] /[\mathrm{Ti}]=5,000 . \mathrm{eg} \mathrm{mol}^{-1}$.

Styrene polymerization studies involving tris(pyrazolyl) borate titanium catalysts

Table 2 summarizes the results for styrene polymerization with titanium pre-catalysts $\mathrm{Tp}^{\prime} \mathrm{TiCl}_{3}\left(\mathbf{3}, \mathrm{Tp}{ }^{\prime}=\mathrm{Tp}^{\mathrm{Ms}} ; \mathbf{4}\right.$, $\mathrm{Tp}^{\prime}=\mathrm{Tp}^{\mathrm{Ms}}$ ) with MAO activation. The more sterically open pre-catalyst 4 showed similar activity $(26.0 \mathrm{~kg}$ of PS mol $\left[\mathrm{Ti}^{-1} \mathrm{~h}^{-1}\right)$ with respect to that one found for $3(22.4 \mathrm{~kg}$ of PS mol $\left[\mathrm{Ti}^{-1} \mathrm{~h}^{-1}\right.$ ) indicating that the presence of one mesityl group at 5-position of the pyrazolyl ring $\left(\mathrm{Tp}^{\mathrm{Ms}}\right)$ does not provide significant influence on the coordination of styrene to the titanium metal center as observed for the nickel pre-catalysts (1-2). In both cases, very low styrene conversion have been obtained reaching no more than $2 \%$ of the total amount of styrene in the polymerization medium.

The resultant polymers produced by 3-4 were characterized as a mixture of polystyrenes with different stereo-regularity. For instance, the extraction with boiling methylethylketone carried out for the polymer sample obtained in entry 17 determines a composition formed by atactic ( $87 \mathrm{wt} . \%)$ and syndiotactic fraction (13 wt.\%) (Scheme 1).

The syndiotactic stereo-regularity was confirmed by presence of an endothermic peak centered at $267^{\circ} \mathrm{C}$ as can

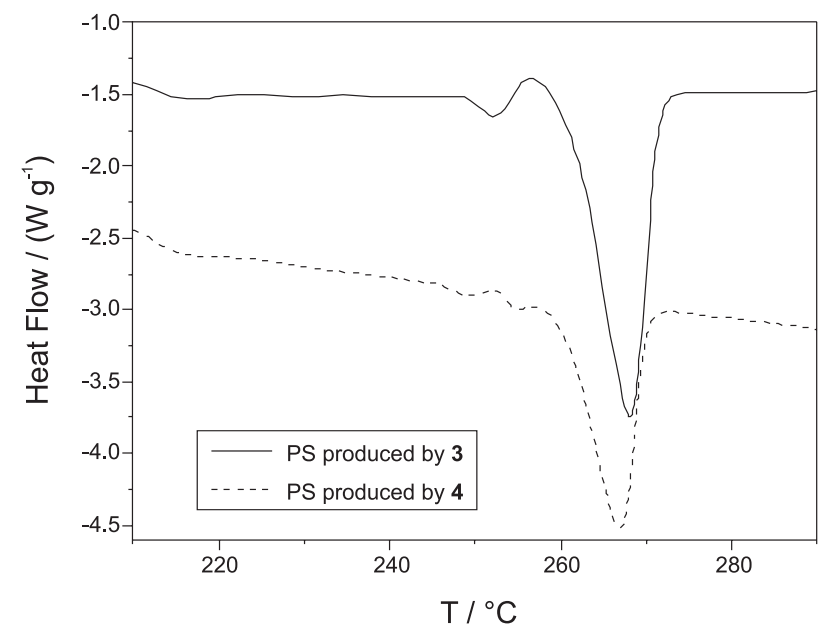

Figure 6. DSC thermograms of the PS produced by 3 and $\mathbf{4}$.

be seen in Figure 6. The formation of two different types of PS can be associated with the presence of more than one catalytic species in the polymerization medium as already demonstrated in previous ethylene polymerization studies involving 3-4/MAO catalytic systems. ${ }^{13}$

The GPC results showed the formation of polystyrene with moderate molecular weight $\left(\mathrm{M}_{\mathrm{w}}=92,500-97,300\right)$ and broad molecular weight distribution $\left(\mathrm{M}_{\mathrm{w}} / \mathrm{M}_{\mathrm{n}}=6.2-6.8\right)$.<smiles>C=Cc1ccccc1</smiles>

$$
\begin{gathered}
\underset{\mathrm{Tp}^{\prime} \mathrm{TiCl}_{3}}{\stackrel{{ }^{\circ} \mathrm{C}, \mathrm{MAO}}{\longrightarrow}} \\
\mathrm{Tp}^{\prime}=\mathrm{Tp}^{\mathrm{Ms}}, \mathrm{Tp}^{\mathrm{Ms}^{*}}
\end{gathered}
$$

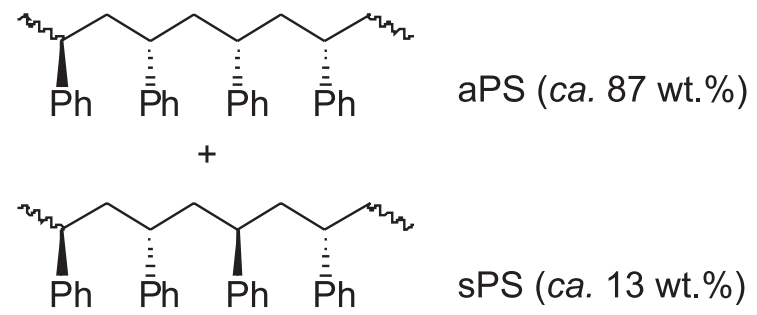

Scheme 1. 
Broad polydispersities can occur if more than one active species is present, or if the ratio of the chain propagation rate to the chain transfer rate $\left(\mathrm{R}_{\text {prop }} / \mathrm{R}_{\text {trans }}\right)$ changes during the time of polymerization. The latter situation can arise if the concentration and/or structure of the chain transfer agent changes during the course of the polymerization.

To probe the possibility of chain transfer to aluminum and the origin of the broad molecular weight distributions, the influence of the MAO concentration on molecular weight was studied using pre-catalyst 4 . As summarized in Table 2, molecular weight decrease as the MAO concentration is increased. For example, when the [Al]/[Ti] molar ratio is increased from 500 to 1000 , the molecular weight decreases from 92,500 to 49,800 (entry 17 vs. 19). In addition, increasing the MAO concentration also narrows the molecular weight distribution varying from 6.8 to 3.3. These observations are consistent with efficient chain transfer to aluminum and it is in agreement with the previous ethylene polymerization results involving titanium pre-catalysts $3-4{ }^{13}$

Taking into account the higher activity of the catalytic systems based on $\mathbf{4}$, this complex was chosen to investigate the effect of temperature and polymerization time on activity and molecular weight. The optimal operating temperature for this pre-catalyst is $80^{\circ} \mathrm{C}$. At $30{ }^{\circ} \mathrm{C}$ it is not observed any production of PS. The molecular weight of the polystyrenes are dependent of the polymerization temperature varying from $92.5 \times 10^{3} \mathrm{~g} \mathrm{~mol}^{-1}$ (entry 17) when the polymerization reaction was performed at $60^{\circ} \mathrm{C}$ to $56.2 \times 10^{5} \mathrm{~g} \mathrm{~mol}^{-1}$ at $80^{\circ} \mathrm{C}$ (entry 18 ). We may reasonably assume that favored formation of PS with lower molecular weight at $80^{\circ} \mathrm{C}$ is a consequence of enhanced rates of chain transfer and/or $\beta$-H elimination.

The activity for the pre-catalyst $\mathbf{4}$ is also dependent on the polymerization time (Figure 7). A maximum activity is reached after an induction time of $60 \mathrm{~min}$ where after the activity decreases. In this case, the apparent decrease in the activity can be attributed to the deactivation of catalytically-active species taking into account that the styrene concentration remains almost unchanged during the polymerization reaction in consequence of very low styrene conversion promoted by 4 .

Conversely to the results obtained using nickel catalyst system 2/MAO, the molecular weight of the PS produced by $4 / \mathrm{MAO}$ is time dependent varying from 38.8 (15 min, entry 20) to $138.3 \times 10^{3} \mathrm{~g} \mathrm{~mol}^{-1}$ (240 min, entry 22 ). This result seems to suggest that the chain propagation rate is faster than the chain transfer process during the period of polymerization. Moreover, the almost invariable styrene concentration during the polymerization process can also contribute to increase the polymer chain.

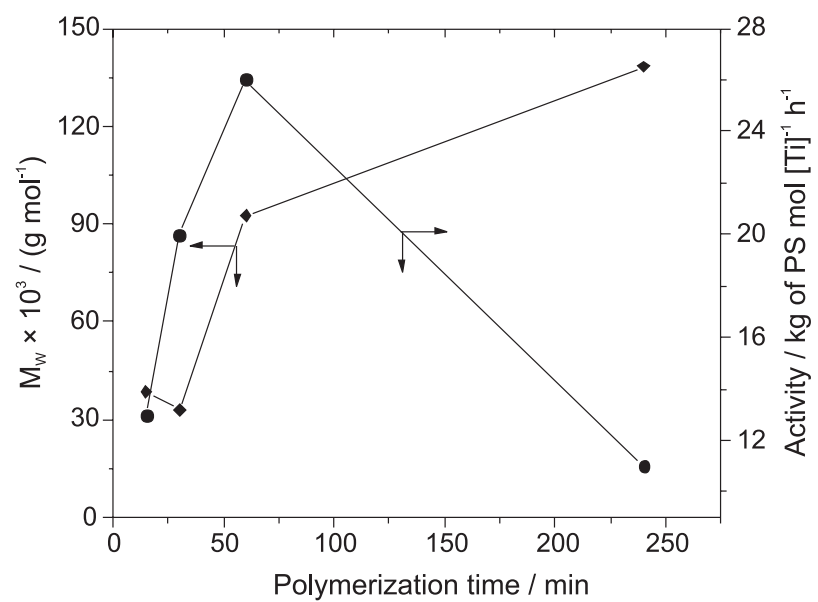

Figure 7. Dependence of polymerization activity and molecular weight on polymerization time with $4 / \mathrm{MAO}$ system at $60^{\circ} \mathrm{C}$ and using [Al]/[Ti] molar ratio of 500 .

In summary, we have demonstrated that nickel(II) and titanium(IV) complexes based on sterically hindered tris(pyrazolyl)borate ligands $\left(\mathrm{Tp}^{\mathrm{Ms}}\right.$ and $\mathrm{Tp}^{\mathrm{Ms}}$ ) are able to polymerize styrene under MAO activation. The nickel pre-catalysts display much higher activities for styrene polymerization than the corresponding titanium precatalysts. In general, these catalytic systems produced atactic PS indicating that the activation of 1-4 with MAO does not lead to the formation of stereospecific active species. The steric properties of the Tp ligands were found to play influence on the activity being this effect more pronounced for the nickel catalysts. The molecular weight of the PS decreases as the temperature is enhanced in the milieu taking into account that the chain transfer rate increases with temperature faster than chain propagation.

\section{Acknowledgments}

This research was financially supported in part by the CNPq and by Pronex/FAPERGS (Brazil). M. C. A. Kuhn, J. L. da Silva and A. C. A. Casagrande gratefully acknowledge CAPES and CNPq for fellowships.

\section{References}

1. Gibson, V. C.; Spitzmesser, S. K.; Chem. Rev. 2003, 103, 283; Ittel, S. D.; Johnson, L. K.; Brookhart, M.; Chem. Rev. 2000, 100, 1169.

2. Wang, W.; Fujiki, M.; Nomura, K.; J. Am. Chem. Soc. 2005, 127, 4582; Hu, T.; Tang, L.-M.; Li, X.-F.; Li, Y.-S.; Hu, N.-H.; Organometallics 2005, 24, 2628; Tsukahara, T.; Furuyama, R.; Mitani, M.; Mohri, J. I.; Mori, R.; Tanaka, H.; Fujita, T.; Macromolecules 2005, 38, 1546; Hustad, P. D.; Coates, G. W.; J. Am. Chem. Soc. 2002, 124, 11578; Stephan, D. W.; 
Guérin, F.; Spence, R. E. V. H.; Koch, L.; Gao, X.; Brown, S. J.; Swabey, J. W.; Wang, Q.; Xu, W.; Zoricak, P.; Harrison, D. G.; Organometallics 1999, 18, 2046; Swenson, D. C.; Jordan, R. F.; Organometallics 1997, 16, 3303; Bei, X.; Swenson, D. C.; Jordan, R. F.; Organometallics 1997, 16, 3282.

3. Lieber, S.; Brintzinger, H.-H.; Macromolecules 2000, 33, 9192.; Resconi, L.; Piemontesi, F.; Franciscono, G.; Abis, L.; Fiorani, T.; J. Am. Chem. Soc. 1992, 114, 1025.; Kim, I.; Choi, C.-S.; J. Polym. Sci., Part A: Polym. Chem. 1999, 37, 1523; Kukral, J.; Lehmus, P.; Klinga, M.; Leskelä, M.; Rieger, B.; Eur. J. Inorg. Chem. 2002, 1349; Naga, N.; Mizunuma, K.; Polymer 1998, 39, 5059; Leino, R.; Luttikhedde, H. J. G.; Lehmus, P.; Wilén, C.-E.; Sjöholm, R.; Lehtonen, A.; Seppäla, J. V.; Näsman, J. H.; Macromolecules 1997, 30, 3477; Zambelli, A.; Longo, P.; Grassi, A.; Macromolecules 1989, 22, 2186; Soga, K.; Kaminaka, M.; Makromol. Chem. 1993, 194, 1745; Lahelin, M.; Kokko, E.; Lehmus, P.; Pitkänen, P.; Löfgren, B.; Seppäla“, J.; Macromol. Chem. Phys. 2003, 204, 1323; Busico, V.; Cipullo, R.; Chadwick, J. C.; Modder, J. F.; Sudmeijer, O.; Macromolecules 1994, 27, 7538; Barsties, E.; Schaible, S.; Prosenc, M.- H.; Rief, U.; Röll, W.; Weyand, O.; Dorer, B.; Brintzinger, H.-H.; J. Organomet. Chem. 1996, 520, 63.

4. Byun, D.-J.; Kim, S. Y.; Macromolecules 2000, 33, 1921.; Byun, D.-J.; Choi, K.-Y.; Kim, S. Y.; Macromol. Chem. Phys. 2001, 202, 992; Byun, D.-J.; Shin, D.-K.; Kim, S. Y.; Macromol. Rapid Commun. 1999, 20, 419; Hakala, K.; Helaja, T.; Löfgren, B.; Polym. Bull. 2001, 46, 123.

5. Natta, G.; Corradini, P.; Makromol. Chem. 1955, 16, 77; Tomotsu, N.; Ishihara, N.; Newman, T. H.; Malanga, M. T.; J. Mol. Catal. A: Chem. 1998, 128, 167; Po, R.; Cardi, N.; Prog. Polym. Sci. 1996, 21, 47; Schellenberg, J.; Tomotsu, N. Prog. Polym. Sci. 2002, 27, 1925; Ewart, S. W.; Baird, M. C.; Top. Catal. 1999, 7, 1; Pellecchia, C.; Grassi, A.; Top. Catal. 1999, 7, 125; Malanga, M.; Adv. Mater. 2000, 12, 1869; Ishihara, N.; Macromol. Symp. 1995, 89, 553.

6. Natta, G.; J. Polym. Sci. 1955, 16, 143; Xu, G.; Lin, S.; Chin. Polym. Bull. 1993, 1, 20; Xu, G.; Lin, S.; Chin. Polym. Bull. 1994, 2, 67; Xu, G.; Lin, S.; Macromol. Chem., Rapid. Commun. 1994, $15,873$.

7. Thayer, A. M.; Polymer Synthesis Chem. Eng. News 1995, 11, 1; Po, R.; Cardi, N.; Prog. Polym. Sci. 1996, 21, 47.

8. Ishihara, N.; Seimiya, T.; Kuramoto, M.; Uoi, M.; Macromolecules 1986, 19, 2464; Ishihara, N.; Kuramoto, M.; Uoi, M.; Macromolecules 1988, 21, 3356; Tomotsu, N.; Ishihara, N.; Newmann, T. H.; Malanga, M. T.; J. Mol. Catal. A: Chem. 1998, 128, 167.
9. Bialek, M.; Cramail, H.; Deffieux, A.; Guillaume, S. M.; Eur. Polym. J. 2005, 41, 2678; Schellenberg, J.; Eur. Polym. J. 2006, 42, 487; Gao, H.; Pei, L.; Song, K.; Wu, Q.; Eur. Polym. J. 2007, 43, 908; Ascenso, J. R.; Dias, A. R.; Gomes, P. T.; Romão, C. C.; Pham, Q-T.; Neibecker, D.; Revillon, A.; Tkatchenko, I.; Macromolecules 1996, 29, 4172; Ascenso, J. R.; Dias, A. R.; Gomes, P. T.; Romão, C. C.; Pham, Q-T.; Neibecker, D.; Tkatchenko, I.; Macromolecules 1989, 22, 1000.

10. Scheirs, J.; Kaminsky, W.; Metallocene-Based Polyolefins, Vol. 2; Wiley: Chichester, 2000; Minieri, G.; Corradini, P.; Zambelli, A.; Guerra, G.; Cavallo, L.; Macromolecules 2001, 34, 2459.

11. Kaminsky, W.; Lenk, S.; Macromol. Symp. 1997, 118, 45; Ready, T. E.; Gurge, R.; Chien, J. C. W.; Rausch, M. D.; Organometallics 1998, 17, 5236.

12. Grassi, A.; Pellecchia, C.; Oliva, L.; Laschi, F.; Macromol. Chem. Phys. 1995, 196, 1093; Pellecchia, C.; Pappalardo, D.; Oliva, L.; Zambelli, A.; J. Am. Chem. Soc. 1995, 117, 6593; Grassi, A.; Saccheo, S.; Zambelli, A.; Laschi, F.; Macromolecules 1998, 31, 5588; Xu, G. X.; Cheng, D. L.; Macromolecules 2000, 33, 2825.

13. Kunrath, F. A.; de Souza, R. F.; Brooks, N. R.; Young Jr., V. G.; Casagrande Jr, O. L.; Organometallics 2003, 22, 4739; Murtuza, S.; Casagrande Jr., O. L.; Jordan, R. F.; Organometallics 2002, 21, 1882; Gil, M. P.; dos Santos, J. H. Z.; Casagrande Jr., O. L.; Macromol. Chem. Phys. 2001, 202, 319; Furlan, L. G.; Gil, M. P.; Casagrande Jr., O. L.; Macromol. Rapid Commun. 2000, 21, 1054; Gil, M. P.; dos Santos, J. H. Z.; Casagrande Jr., O. L.; J. Mol. Catal. A: Chem. 2004, 209, 163; Furlan, L. G.; Casagrande Jr., O. L.; J. Braz. Chem. Soc. 2005, 16, 1248; Casagrande, A. C. A.; Gil, M. P.; Casagrande Jr, O. L.; J. Braz. Chem. Soc. 2005, 16, 1283.

14. Tellers, D. M.; Skoog, S. J.; Bergman, R. G.; Gunnoe, T. B.; Arman, W. D.; Organometallics 2000, 19, 2428.

15. Space-filling model calculated using Mercury program (version 1.4.2) based on the X-ray crystallographic parameters for $\mathbf{1}$ (reference 13).

16. Bochmann, M.; Lancaster, S. J.; Angew. Chem., Int. Ed. 1994, 33, 1634; Kim, I.; Jordan, R. F.; Macromolecules 1996, 29, 489; Tritto, I.; Donetti, R.; Sacchi, M. C.; Locatelli, P.; Zannoni, G.; Macromolecules 1997, 30, 1247; Coevoet, D.; Cramail, H.; Deffieux, A.; Mladenov, C.; Pedeutour, J.-N.; Peruch, F.; Polym. Int. 1999, 48, 257; Pédeutour, J.-N.; Coevoet, D.; Cramail, H.; Deffieux, A.; Macromol. Chem. Phys. 1999, 200, 1215.

Received: May 22, 2008 Web Release Date: September 29, 2008 